Aleksandra Ttuściak-Deliowska, Monika Czyżewska

Poland

\title{
Formative Assessment Practices and the School Social Climate. A New Approach to the Subject Based on a Study Conducted in Poland
}

DOI: 10.15804/tner.2019.55.1.02

\begin{abstract}
The topic of formative assessment has rarely been addressed in Polish educational research studies, and the connection between formative assessment and the school climate has, until now, never been examined. The subject of this quantitative study were the formative assessment practices used by elementary school teachers and the school social climate. The participants were students $(\mathrm{N}=491)$ and teachers $(\mathrm{N}=60)$. Findings indicate that: $(1)$ to a varying degree, teachers use activities that make up formative assessment, (2) schools differ significantly in their formative assessment practices, (3) the social climate at these schools is positive, (4) formative assessment practices are positively correlated with the school climate.
\end{abstract}

Keywords: formative assessment, school climate, feedback, interpersonal relationships, learning process

\section{Introduction}

Formative assessment (FA) has been present in western education practices for several decades. It is usually regarded as a highly effective set of techniques and strategies, helpful not only in the assessment of students' work and progress, but also in the process of learning per se. The underlying assumption behind FA is 
based on the interpersonal skills of the teacher and the development of these skills in the student, which may help facilitate the building of a culture of communication for all participants. The impetus for research in this area came on reflection that although the school social climate (SSC) is a concept that is usually applied to the relational aspects of the functioning of a school, there is no evidence of its correlation with assessment, especially with the type of assessment which is founded on relational grounds - that of formative assessment. Consequently, this raised the question as to whether there is a relation between FA and the SSC. This became the basis for the conceptual framework of the research.

\section{Formative Assessment Practices}

Formative assessment is a set of planned and interrelated teacher activities, the implementation of which helps to create greater effectiveness of learning. It is an ongoing, dynamic process and it gives information during the instructional process (summative assessment usually does this after the completion of either an element of or the whole instructional process). The aim of FA is to get information on how a student acquires knowledge and therefore identify the student's educational needs in order to introduce a more effective learning process. The essence of FA comprises the feedback in which students are informed as to how well they did in their work, what should be done differently, what and how should be corrected and what may be done to further develop skills and knowledge (Glazer, 2014, p. 277). According to Wiliam, there are five core strategies in FA practice:

1. Clarifying learning intentions and sharing criteria for success.

2. Engineering effective classroom discussions, questions, and learning tasks that elicit evidence of learning.

3. Providing feedback that fosters a sense of learner progression.

4. Activating students to think of themselves as the owners of their own learning.

5. Activating students to think of themselves as instructional resources for one another (Wiliam, 2007, p. 192).

These assumptions are already widespread in Poland, and schools that apply FA function rely on them to a large extent ${ }^{1}$. These were treated as the basis for the development of a tool for research that will be the subject of the presentation in this text.

1 Strategies of formative assessment have been present in several Polish schools for almost 20 years. However, these remain in a minority, and often comprise isolated elements rather than occurring in every aspect of instruction and school assessment criteria. The basis are the guidelines presented in numerous works by Danuta Sterna. 


\section{The School Social Climate}

In analyzing the characteristics of the school environment, it is difficult to find a clear and precise definition of the school climate. This is mainly because literature defines the school climate from several different points of view and from different research perspectives. The American National School Climate Center has compiled the key areas of the school climate (Thapa et al., 2012): (1) the quality of social relations, (2) the characteristics of the education and instruction, (3) physical and emotional security, and (4) the characteristics of the physical environment (cf. also: Van Houtte, 2005; Bond, 2017).

It should be noted that the SSC is created during any interaction between "me and others". The authors assume that the socio-emotional climate includes relations between members of the school community and any experiences that are connected to the various events they may witness either at school or in relation to the school. Personal experiences related to the different dimensions of school reality become the basis for a better perception and understanding of the school climate.

\section{From Providing Feedback to Improving the School Social Climate}

The importance of the relational components of feedback, its impact on students and the perception of it, has been widely described (Davis \& Dargusch, 2015, p. 179). The quality of the student-teacher relationship influences the student's perception of the feedback received from the teacher, and in this way, it is a part of the closed circle: giving feedback can influence the quality of the relationship. While Adcroft describes interpersonal relationships in the process of assessment as a fundamental aspect (2011, p. 406), Davis and Dargusch go further and conclude that "relationships can play a mediating role both positively as an enabler, or negatively as a contradiction and barrier in the effective operation of the assessment and feedback system" (Davis \& Dargusch, 2015, p. 179). They also refer to Carless (2009), who draws attention to the aspect of mutual "investment of trust" between a teacher and a student as an imminent part of the assessment practice (Carless, 2009, pp. 82, 87) and proceed to describe the rules of "dialogic feedback", which stands for an opportunity to interact and negotiate for both interlocutors (Davis \& Dargusch, 2015, p. 179).

\section{Research Focus}

The subject of the study were the practices of FA used by elementary school teachers from three schools and the social climate in these schools. The object of 
interest were not simply the strategies and techniques used by the teachers but also the impact of these issues on the perception of the school climate. The following research questions were formulated:

1. What elements of formative assessment practices are used in schools?

2. What is the social climate in these schools?

3. Is there a relation between formative assessment practices and the school social climate?

\section{$\underline{\text { Research Methodology }}$}

\section{Research General Background}

Three Warsaw elementary schools which use FA were invited to participate in the research. The practices labeled as FA in the schools vary widely. School A was established in 1945, FA being introduced there in 2011. School B was built in 1962 and has employed FA since 2008. School C has only recently been opened (2016/17), but elements of FA elements have been in place since that date.

The study was organized as quantitative research in the first phase, and then in the second one as qualitative - in a form of interviews with the view of consolidating and expanding data. This mixed strategy was appropriate as it provided a better insight into research problems.

\section{Research Sample}

The sampling of schools was purposive, as the aim was to reach schools which employ formative assessment and to survey all their teachers and students.

A total of 60 teachers took part in the research (33 respondents from School A, 14 from School B, 14 from School C). The teacher sample consisted of 48 female respondents $(80.0 \%)$ and 11 male ones (18.3\%) (one individual refused to provide the relevant data). The average seniority in the teaching profession among the respondents was 13 years and the average length of service at the school was 7 years.

There were 491 students who took part in the research (227 students from School A, 66 students from School B, 198 students from School C). The student sample consisted of 244 girls (49.4\%) and 229 boys (46.4\%) (21 students did not provide data). The average age of the students was 11.03 years $(\mathrm{SD}=1.27)$.

The demographic characteristics of the participants are presented in Table 1. 
Table 1. Demographic characteristics of research sample

\begin{tabular}{|c|c|c|c|c|}
\hline & & School A & School B & School C \\
\hline Teachers & Gender & & & \\
\hline \multirow[t]{10}{*}{$(n=60)$} & Male & $84.4 \%$ & $92.9 \%$ & $57.1 \%$ \\
\hline & Female & $15.6 \%$ & $7.1 \%$ & $35.7 \%$ \\
\hline & No data & - & - & $7.1 \%$ \\
\hline & Professional degree & & & \\
\hline & Lack of degree & - & $21.4 \%$ & $14.3 \%$ \\
\hline & Trainee teacher & - & - & $64.3 \%$ \\
\hline & Contracted teacher & $21.9 \%$ & $14.3 \%$ & $21.4 \%$ \\
\hline & Appointed teacher & $37.5 \%$ & $28.6 \%$ & - \\
\hline & Certified teacher & $38.5 \%$ & $35.7 \%$ & - \\
\hline & No data & $3.1 \%$ & - & - \\
\hline \multirow{4}{*}{$\begin{array}{l}\text { Students } \\
(\mathrm{n}=491)\end{array}$} & Gender & & & \\
\hline & Male & $54.6 \%$ & $34.8 \%$ & $49.0 \%$ \\
\hline & Female & $42.3 \%$ & $62.1 \%$ & $46.5 \%$ \\
\hline & No data & $3.1 \%$ & $3.0 \%$ & $4.5 \%$ \\
\hline
\end{tabular}

\section{Instruments and Procedures}

This article will only present quantitative results. These are based on the results of two questionnaires: (1) "Formative Assessment Practices Questionnaire. Teacher and Student Form" and (2) "The Climate in my School. Teacher and Student Form"2.

The first questionnaire, which surveyed the topic of FA, was specially prepared for this research project. A version for teachers, with a corresponding questionnaire for students was prepared. Over 30 statements were divided into 4 dimensions or scales: (1) learning goals ( $\alpha=0.88),(2)$ criteria for success $(\alpha=0.82)$, (3) learning activities $(\alpha=85)$ and (4) feedback $(\alpha=0.85)$. Items were included after referring to the literature that reviews the current use of FA in Poland. The respondents were asked to adopt a 4-point response scale ranging from "never" (1), "sometimes" (2), "often" (3) to "always/almost always" (4). The higher the mean score, the greater the intensification of activities focused on a particular aspect of FA.

The second questionnaire was used to assess the perception of the school climate from the teacher's and the student's perspective. The questionnaire "The Climate in my School" includes such dimensions as (1) satisfaction with studying or working at school, (2) relationships between members of the school community,

2 The author of the questionnaire is Magdalena Woynarowska-Sołdan. The questionnaire is available in Polish. 
(3) creating opportunities for members of the school community to participate in school life and work, (4) assessment of interpersonal relations, (5) emotional support, (6) motivating to achieve success, (7) the possibility of effective work during lessons, (8) overload by learning or work at school. To assess them, a fivepoint scale was used: "definitely not" (1), "rather not" (2), "hard to say" (3), "rather yes" (4), "definitely yes" (5). The higher the average rating for any given dimension (with one exception), the more positive the opinion. The last dimension is an exception - in this case, the lower the average value, the better. As with the previous questionnaire, versions for both the teachers and the students were prepared. Although the teachers were asked about how they feel in the workplace and how they would assess it from their own perspectives, bearing in mind the assumptions of the project and this article, only those dimensions of the school climate that focus primarily on the student's situation will be presented. These, it should be pointed out, were assessed by both the students and the teachers.

\section{Research Results}

\section{Formative Assessment Practices in the Schools Analyzed}

Initially, the prevalence of FA practices from the perspective of the teachers was established. In addition, a comparison was made between the schools that participated in the study. This comparison was made because each of these schools has a different experience of applying FA practices. The results are presented in Table 2.

Table 2. Formative Assessment Practices. Teacher's Perspective $(\mathrm{N}=60)$

\begin{tabular}{lcccccccccc}
\hline & \multicolumn{2}{c}{ General } & \multicolumn{2}{c}{ School A } & \multicolumn{2}{c}{ School B } & \multicolumn{2}{c}{ School C } & \multirow{2}{*}{ F } & \multirow{2}{*}{ Sig. } \\
\cline { 2 - 10 } & $\mathrm{M}$ & SD & M & SD & M & SD & M & SD & & \\
\hline Learning goals & 3.15 & .46 & 3.33 & .39 & 2.98 & .50 & 2.95 & .44 & 4.70 & .014 \\
\hline $\begin{array}{l}\text { Criteria for } \\
\text { success }\end{array}$ & 3.39 & .50 & 3.55 & .36 & 3.40 & .56 & 3.04 & .52 & 5.82 & .005 \\
\hline $\begin{array}{l}\text { Learning } \\
\text { activities }\end{array}$ & 3.35 & .36 & 3.40 & .35 & 3.62 & .20 & 3.00 & .24 & 9.03 & .001 \\
\hline Feedback & 3.16 & .36 & 3.29 & .39 & 3.17 & .23 & 2.96 & .33 & 3.58 & .037 \\
\hline
\end{tabular}

Looking at the overall results, it can be concluded that the teachers are mostly involved in defining success criteria and undertaking different didactic activities to orient students to meet these criteria. Results from the one-way ANOVA provide 
information about statistically significant differences between all schools ( $\mathrm{p}<$ 0.05). Post hoc comparisons using the NIR test indicated that the mean score for the "learning goals" in School A $(\mathrm{M}=3.33 ; \mathrm{SD}=0.39)$ differ significantly from that in School B $(\mathrm{M}=2.98 ; \mathrm{SD}=0.50)$ and School C $(\mathrm{M}=2.95 ; \mathrm{SD}=0.44)$. However, there was no statistically significant difference in relation to the activities related to "learning goals" between school A and B. Taking into account the "criteria for success", it was evident that School C had the lowest score $(\mathrm{M}=3.04$; $\mathrm{SD}=0.52)$. Statistically, this was significantly different from those scored by School A ( $\mathrm{M}=$ $3.55 ; \mathrm{SD}=0.36)$ and School $\mathrm{B}(\mathrm{M}=3.40$; $\mathrm{SD}=0.56)$. The same situation was evident in relation to "learning activities". In turn, in relation to the "feedback", a statistically significant difference occurred between school $\mathrm{A}(\mathrm{M}=3.29 ; \mathrm{SD}=$ $0.39)$ and $\mathrm{C}(\mathrm{M}=2.96 ; \mathrm{SD}=0.33)$.

The same analyses were carried out in relation to data obtained from the students (cf., Table 3).

Table 3. Formative Assessment Practices. Students' Perspective ( $N=491)$

\begin{tabular}{|c|c|c|c|c|c|c|c|c|c|c|}
\hline & \multicolumn{2}{|c|}{ General } & \multicolumn{2}{|c|}{ School A } & \multicolumn{2}{|c|}{ School B } & \multicolumn{2}{|c|}{ School C } & \multirow{2}{*}{$\mathrm{F}$} & \multirow{2}{*}{ Sig. } \\
\hline & M & SD & M & SD & $\mathbf{M}$ & SD & M & SD & & \\
\hline Learning goals & 2.77 & .62 & 2.87 & .56 & 2.86 & .70 & 2.64 & .62 & 7.79 & .000 \\
\hline Criteria for success & 3.04 & .65 & 3.12 & .59 & 2.99 & .79 & 2.96 & .67 & 3.36 & .036 \\
\hline Learning activities & 2.81 & .51 & 2.91 & .45 & 2.81 & .67 & 2.69 & .50 & 8.88 & .000 \\
\hline Feedback & 2.59 & .55 & 2.69 & .51 & 2.72 & .57 & 2.41 & .54 & 14.39 & .000 \\
\hline
\end{tabular}

The table shows that the average scores obtained on the basis of data from the students are lower than those of the teachers and that the differences between the schools are not so pronounced, although they remain statistically significant $(p<$ 0.001 ; except "criteria for succes" $p<0.05$ ). Post hoc comparisons using the NIR test indicated that the mean score for the "learning goals" in School C $(\mathrm{M}=2.64$; $\mathrm{SD}=0.62)$ differs significantly from those in School $\mathrm{B}(\mathrm{M}=2.86 ; \mathrm{SD}=0.70)$ and School A $(\mathrm{M}=2.87 ; \mathrm{SD}=0.56)$. Statistically, some important differences occurred between School A $(M=3.12$; $S D=0.59)$ and School C $(M=2.96$; SD 0.67) when considering the "criteria for success" among students. The same situation was evident in relation to "learning activities". However, as regards "feedback", it turned out that School B $(M=2.72 ; S D=0.57)$ differs significantly from School $C(M=$ $2.41 ; \mathrm{SD}=0.54)$. 


\section{Teachers' and Students' Perception of the School Social Climate}

The analyses of the school climate perception were analogous to the FA practices analyses. The presentation of the results focused on the comparison of the teachers' and students' perception of the school climate. The figure below (Figure 1) presents a comparison of the average values for the dimension of the school climate.

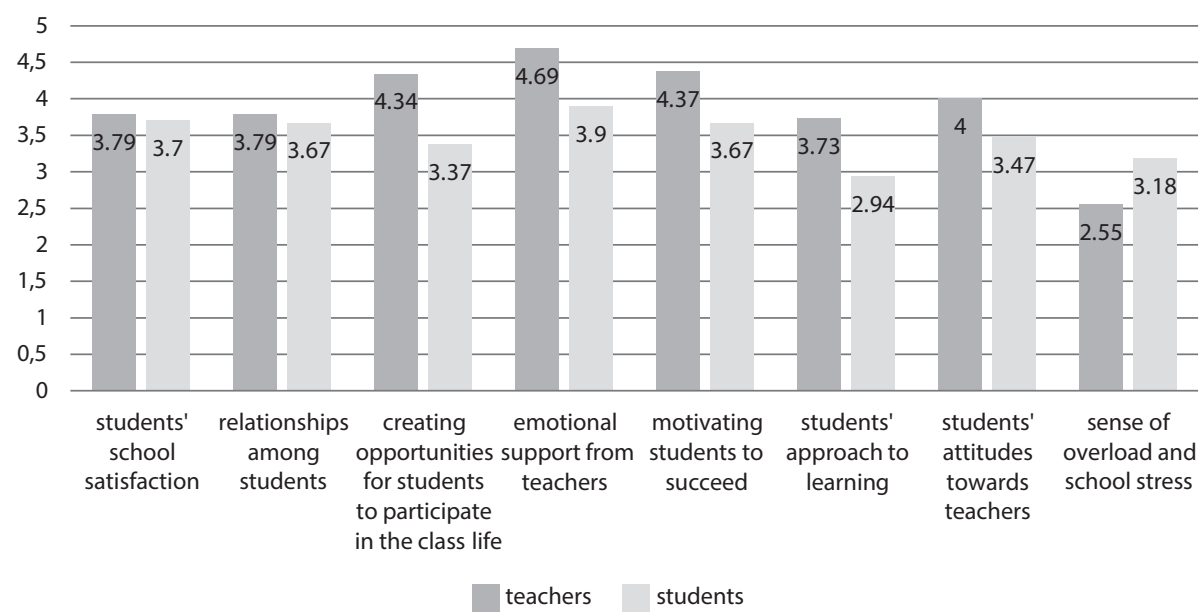

Figure 1. Comparison of the perception of the school social climate by teachers and students

The teachers gave the highest ratings to those dimensions that directly concern their actions in the classroom, e.g., "emotional suppport from teachers" ( $M=$ 4.69; $\mathrm{SD}=0.45)$, "motivating students to succeed" $(\mathrm{M}=4.37$; $\mathrm{SD}=0.57)$, "creating opportunities for students to participate in class life" $(\mathrm{M}=4.34$; $\mathrm{SD}=0.52)$. The students' assessment of the school climate dimensions was often lower than that of the teachers, with the exception of the students' "sense of overload and school stress". The fact that the number of the teachers was lower than the number of the students taking part in the study resulted in the Mann Whitney nonparametric test being employed to compare the results. The analysis of this test showed that the teachers rank the school climate significantly higher than the students $(\mathrm{p}<0.05)$, with the following exceptions: "students' school satisfaction" and "relationships among students". In these two cases the responses were similar. 


\section{Relationships between Formative Assessment Practices and the School Social Climate}

The last step of the analysis involved the relationships between the main variables. As there were two data sources (teachers and students) and also that there were some significant differences in the students' and teachers' perspectives regarding both FA practices and the school climate dimensions, correlation analyses were conducted separately for data obtained from the teachers and students. The results of the correlation analysis are presented in Table 4.

Table 4. Correlations coefficients: formative assessment practices and the school social climate dimensions

\begin{tabular}{|c|c|c|c|c|c|c|c|c|}
\hline \multicolumn{9}{|c|}{ Based on data from teachers } \\
\hline & (1) & (2) & (3) & (4) & (5) & (6) & $(7)$ & (8) \\
\hline Learning goals & .18 & $.30^{*}$ & $.56^{\star *}$ & $.43^{* *}$ & $.52^{* *}$ & $.35^{\star}$ & $.34^{*}$ & .04 \\
\hline Criteria for success & $.28^{\star}$ & $.43^{\star *}$ & $.62^{* *}$ & $.40^{* *}$ & $.49^{* *}$ & $.41^{\star *}$ & $.38^{\star *}$ & -.02 \\
\hline Learning activities & .26 & $.43^{*}$ & $.63^{* *}$ & .36 & $.58^{\star *}$ & $.43^{*}$ & $.43^{*}$ & -.06 \\
\hline Feedback & $.32^{*}$ & $.41^{* *}$ & $.70^{* *}$ & $.43^{* *}$ & $.65^{* *}$ & $.40^{* *}$ & $.56^{\star *}$ & .07 \\
\hline
\end{tabular}

Based on data from students

\begin{tabular}{|c|c|c|c|c|c|c|c|c|}
\hline Learning goals & $.47^{* *}$ & $.38^{\star *}$ & $.48^{\star *}$ & $.53^{\star *}$ & $.55^{\star *}$ & $.38^{* *}$ & $.36^{* *}$ & -.01 \\
\hline Criteria for success & $.47^{\star \star}$ & $.40^{\star *}$ & $.49^{* *}$ & $.54^{\star *}$ & $.50^{\star \star}$ & $.35^{\star *}$ & $.30^{\star *}$ & -.07 \\
\hline Learning activities & $.44^{* *}$ & $.41^{\star *}$ & $.43^{* *}$ & $.53^{* *}$ & $.49^{* *}$ & $.37^{* *}$ & $.32^{* *}$ & -.07 \\
\hline Feedback & $.47^{\star \star}$ & $.38^{\star *}$ & $.48^{\star *}$ & $.57^{\star *}$ & $.58^{\star *}$ & $.43^{* *}$ & $.35^{\star *}$ & -.06 \\
\hline
\end{tabular}

(1) - students' school satisfaction

(2) - relationships among students

(3) - creating opportunities to participate in the class life

(4) - emotional support from teachers

(5) - motivating students to succeed

(6) - students' approach to learning

(7) - students' attitude towards teachers

(8) - sense of overload and school stress

* correlation is significant at the 0.05 level (2-tailed); ${ }^{* *}$ correlation is significant at the 0.01 level (2-tailed)

It transpired that the practices constituting FA display a significant positive relation to the school climate dimensions, with the exception of the "sense of overload and school stress". Correlations for individual dimensions range from low to moderate in most cases, whilst some are strong. Based on the teachers' perspective, it can be concluded that the activities comprising FA show a significant correlation, 
especially regarding the actions of teachers who are focused on providing support and motivation and the creation of opportunities to participate in the life of the class. This has also been confirmed by analyses based on data from the students. It is worth noting that FA practices positively correlate with the students' overall school satisfaction.

\section{Discussion}

The study explored (1) FA practices in three schools, which had been specifically selected for the study, (2) the perception of the social climate in these schools and (3) the relationships between FA practices and the school climate. The source of the data was information obtained from students and teachers. Findings indicate that: (1) the teachers use - to a varying degree - the activities that comprise formative assessment in their everyday didactic approach to work, (2) as regards FA practices, the three schools differ significantly, (3) the social climate in these schools is, in general, positive, (4) there is a differentiation in the perception of the school climate between the students and teachers, (5) FA practices are positively correlated with the school climate dimensions.

Based on the results, it can be assumed that the teachers take into account various activities aimed at informing students about the goal of the class and the criteria of success. They implement different methods which involve students in the learning process and use differentiated strategies for providing feedback. When comparing the perspectives of the teachers and students, there was a marked differentiation in the assessment of the intensity of individual activities. The teachers regularly pointed to higher frequencies than the students. This result can be explained in at least two ways. Firstly, the teachers undertake various activities that combine to make up assessment; they also participate in training sessions to prepare for particular classroom activities, which draw attention to their purpose. Therefore, it is easier for them to assess which of the activities they apply and the extent to which they are applied, while the students may not always be conscious of the techniques used by the teachers. On the other hand, the teachers tend to be conscious of the need to make a good impression during research whenever they are being asked directly about their professional activities. Consequently, the teachers, who consider themselves to be representatives of a specific professional group, may want to "do well", while the students may be more willing to make comments about real behaviors. A similar contrast between teacher and student perceptions also occurred when school climate responses were compared. 
Referring to the formative assessment, it should be noted that there were significant differences in FA practices between the three schools involved in the survey. This was the most intense at school A and School B, while school C recorded the lowest level of FA activity. This corresponds, to some extent, to the formative asessment experience of these schools. Schools A and B are the most experienced, which may explain the emphasis put on such matters as goal setting, criteria for success and the employment of various didactic activities aimed at allowing students to achieve their goals, and which conclude with complete and comprehensive feedback.

The analysis of the data collected allowed the researchers to conclude that the SSC in the schools involved in the study is positive. However, there is a marked differentiation in the perception of the school climate between the students and teachers. This is a fairly typical situation regarding such assessments (cf. also: Dernowska, 2017). Teachers frequently assess the majority of the dimensions of the climate significantly higher than students. However, there is a suggestion that the school climate dimensions that were analyzed were actually closer to the students' perspective. For example, while the teachers referred to how they think students feel at school or how they perceive teachers' actions or what the students' attitude to learning is, it ought to be noted that the students' actual perspective may be closer to the truth. However, it should also be noted that in the area of general school assessment (satisfaction with school) and the general assessment of the relationship between students, the responses of the teachers and students were similar. The coherence of positions on these issues supports the results obtained and may also indicate that the teachers have a good orientation as regards the situation of their students.

In conclusion, the result of the study is that FA practices are positively correlated with the school climate dimensions. Some particularly important correlations concerned FA practices in connection with the perception of the teacher's activities by the students. The teachers who use FA are simultaneously perceived by the students as being more motivational and more supportive of their full participation in activities during class time. Furthermore, the teachers' activities, included in the broadly understood formative assessment, showed a significant correlation with the students' overall satisfaction. This is an important result because it means that students in a school that uses FA practices feel good and like their school. 


\section{Conclusions}

The research was exploratory in nature, especially with regard to formative assessment, which has not been subject to comprehensive study in Poland. As a result, it is of particular interest when dealing with the analysis of the characteristics of the "Polish application" of FA, while the examination of the relation between formative assessment practices and the school climate is both innovative and important for both the Polish and non-Polish contexts. The authors believe that in that way this work will go some way towards building understanding in the wider context of education in general.

\section{Acknowledgements}

The research was carried out as a part of the BSTP 16/17 - I WNP APS project.

The results presented in this paper are the subject of a paper presented at the XI International Congress of Educational Research, which took place on $17^{\text {th }}-19^{\text {th }}$ September 2018 at the Pedagogical University of Cracow, Poland.

\section{References}

Adcroft, A. (2011). The mythology of feedback. Higher Education Research \& Development, 30(4), 405-419.

Bond, J.B. (2017). How School Leaders Can Use Formative Assessment Strategies. International Dialogues on Education, 4(1), 150-159.

Carless, D. (2009). Trust, Distrust and their Impact on Assessment Reform. Assessment \& Evaluation in Higher Education, 34(1), 79-89.

Davis, S.E., Dargusch, J.M. (2015). Feedback, Iterative Processing and Academic Trust Teacher Education Students' Perceptions of Assessment Feedback. Australian Journal of Teacher Education, 40(1), 176-191.

Dernowska, U. (2017). Teacher and Student Perceptions of School Climate. Some Conclusions from School Culture and Climate Research. Journal of Modern Science, 32(1), 63-82.

Glazer, N. (2014). Formative Plus Summative Assessment in Large Undergraduate Courses: Why Both? International Journal of Teaching and Learning in Higher Education, 26(2), 276-286.

Thapa A., Cohen J., Higgins-D’Alessandro A., Guffey S. (2012). School Climate Research Summary. National School Climate Center: School Climate Brief, 3, August 2012.

Van Houtte, M. (2005). Climate or culture? A plea for conceptual clarity in school effectiveness research. School Effectiveness and School Improvement, 16(1), 71-89.

Wiliam, D. (2007), Content Then Process: Teacher Learning Communities in the Service of Formative Assessment, in: D. Reeves (ed.), Ahead of the Curve: The Power of Assessment to Transform Teaching and Learning (pp. 183-204). Bloomington: Solution Tree Press. 